\title{
Paravertebral Blocks: Anatomical, Practical, and Future Concepts
}

\author{
Amit Pawa ${ }^{1} \cdot$ Thomas Wojcikiewicz $^{2} \cdot$ Ann Barron $^{2} \cdot$ Kariem El-Boghdadly ${ }^{1,3}$
}

Published online: 11 April 2019

(C) The Author(s) 2019

\begin{abstract}
Purpose of Review This article aims to review the thoracic paravertebral block by discussing the relevant anatomy, and landmark and ultrasound-guided techniques. We will compare analgesic efficacy to established neuraxial techniques as well as discuss the complications.

Recent Findings The quality of analgesia is comparable and non-inferior to epidural analgesia, especially for surgery involving a thoracotomy. The evidence regarding its use in abdominal surgery is not clear. There are long-term analgesic benefits for thoracic paravertebral blocks in breast surgery and it might potentially play a role in modulating cancer recurrence. Furthermore, latest research suggests an efficacious block can be achieved with a less invasive approach to the paravertebral space.

Summary The paravertebral block can achieve analgesia comparable to thoracic epidural, the use of ultrasound improves block success, and the complication rates are low. Novel techniques are emerging which might change the approach to the block in the future.
\end{abstract}

Keywords Paravertebral blocks $\cdot$ Paravertebral space $\cdot$ Ultrasound $\cdot$ Complications

\section{Introduction}

The paravertebral block is a regional anesthetic technique that provides ipsilateral anesthesia and analgesia resulting in somatic and sympathetic blockade in a continuous dermatomal manner. It was first performed in the early 1900 s with the aim of providing analgesia for abdominal surgery, but its use was subsequently adopted in a variety of non-surgical conditions such as angina pectoris, herpes neuralgia, and analgesia for fractured neck of femur [1]. It is now an established technique and can be used to provide analgesia for acute and chronic pain conditions of the thorax and abdomen $[2,3 \bullet]$. The benefits are well documented [4] with analgesic qualities comparable to epidural anesthesia, which is often seen as the "gold

This article is part of the Topical Collection on Regional Anesthesia

Amit Pawa

amit.pawa@gstt.nhs.uk

1 Department of Anaesthesia, Guy's and St Thomas' NHS Foundation Trust, Great Maze Pond, London SE1 9RT, UK

2 Specialty Trainee, Guy's and St Thomas' NHS Foundation Trust, London, UK

3 Honorary Senior Lecturer, King's College London, London, UK standard" for analgesia of the thorax and abdomen [5•]. The block can be performed unilaterally, bilaterally, as a single injection, or with a continuous catheter technique. Before the use of ultrasound, the landmark technique was adopted, but this has more recently been superseded by ultrasound-guided techniques. Although lumbar paravertebral blocks have been performed for abdominal procedures $[3 \cdot, 6]$, there are uncertainties regarding the existence of the lumbar paravertebral space, and the block is most commonly performed in the thoracic region and are hence termed the thoracic paravertebral block (TPVB).

As well as favorable acute pain outcomes, evidence is beginning to emerge regarding the benefits of the TPVB and long-term chronic pain [7] and the ability to utilize the technique in order to avoid general anesthesia [8]. Furthermore, the role that anesthesia, particularly volatiles and opioids, plays in cancer cell biology and ultimately tumour metastases and recurrence has begun to be evaluated [9-11]. Therefore, the role of local and regional anesthetic techniques might become more important as further evidence emerges.

This article aims to review the TPVB by covering the anatomy, landmark and ultrasound-guided approaches, analgesic efficacy, and complications. Furthermore, it will aim to summarize novel techniques to accessing the paravertebral space (PVS), the so-called paravertebral by proxy techniques [12•]. 


\section{Anatomical Concepts}

The anatomy of the paravertebral space is classically described as being wedge shaped which runs continuously and bilaterally from $\mathrm{T} 1$ to $\mathrm{L} 1$, lying either side of the vertebral column. It is a potential space containing fatty tissue within which lie the intercostal nerves, arteries, and veins, accompanied by the sympathetic trunk (Fig. 1). The apex of the wedge lies laterally and communicates with the intercostal spaces. The base of the wedge lies medially, adjacent to the thoracic spine, between the lateral border of the vertebral body and transverse process. The dorsal and ventral roots of the spinal nerve pass through this border. The posterior border of the paravertebral space is formed by the superior costotransverse ligament (SCTL) which runs between the lower border of the transverse process above and the upper border of the rib below. A group of costotransverse ligaments offer stability to the rib cage [13] and consist of a number of sets of fibers. The ligament is said to be porous in nature due to gaps at the medial or lateral borders [14] or fenestrations in the ligament itself [15].

The posterior musculature is important to recognize, especially as these are the focus of newly described fascial plane blocks [2]. The erector spinae, rhomboid (T2 to T5), and trapezius (up to T12) muscles all sit posteriorly to the transverse process. An antero-lateral border is formed along the line of the parietal pleura underneath which sits the lung. The psoas muscle at the level of L1 is thought to be the lower border of the space [16], although this inferior border has been disputed by evidence of somatic blocks achieved as distal as the level of L3 [17].

\section{Landmark-Guided Thoracic Paravertebral Block}

A number of techniques for thoracic paravertebral block have been described [18-20] but the "classical" landmark-guided TPVB technique was comprehensively summarized by Eason and Wyatt in 1979 based on anatomical landmarks [18]. They performed over 25 single-injection and over 50 continuous catheter block techniques with good analgesic results and reported one accidental pleural puncture and three cannulations of a blood vessel with the catheter.

The block can be performed with the patient in either the sitting, lateral, or prone positions. A needle, typically an 80 $\mathrm{mm}, 16-\mathrm{G}$ Tuohy needle, is inserted at $90^{\circ}$ to the skin, approximately three centimeters lateral to the midline of the spine, the palpable landmark being the superior aspect of the patient's spinous process. Contact with the transverse process is felt and then the needle is directed either cephalad or caudad and advanced beyond the transverse process to breach the SCTL.

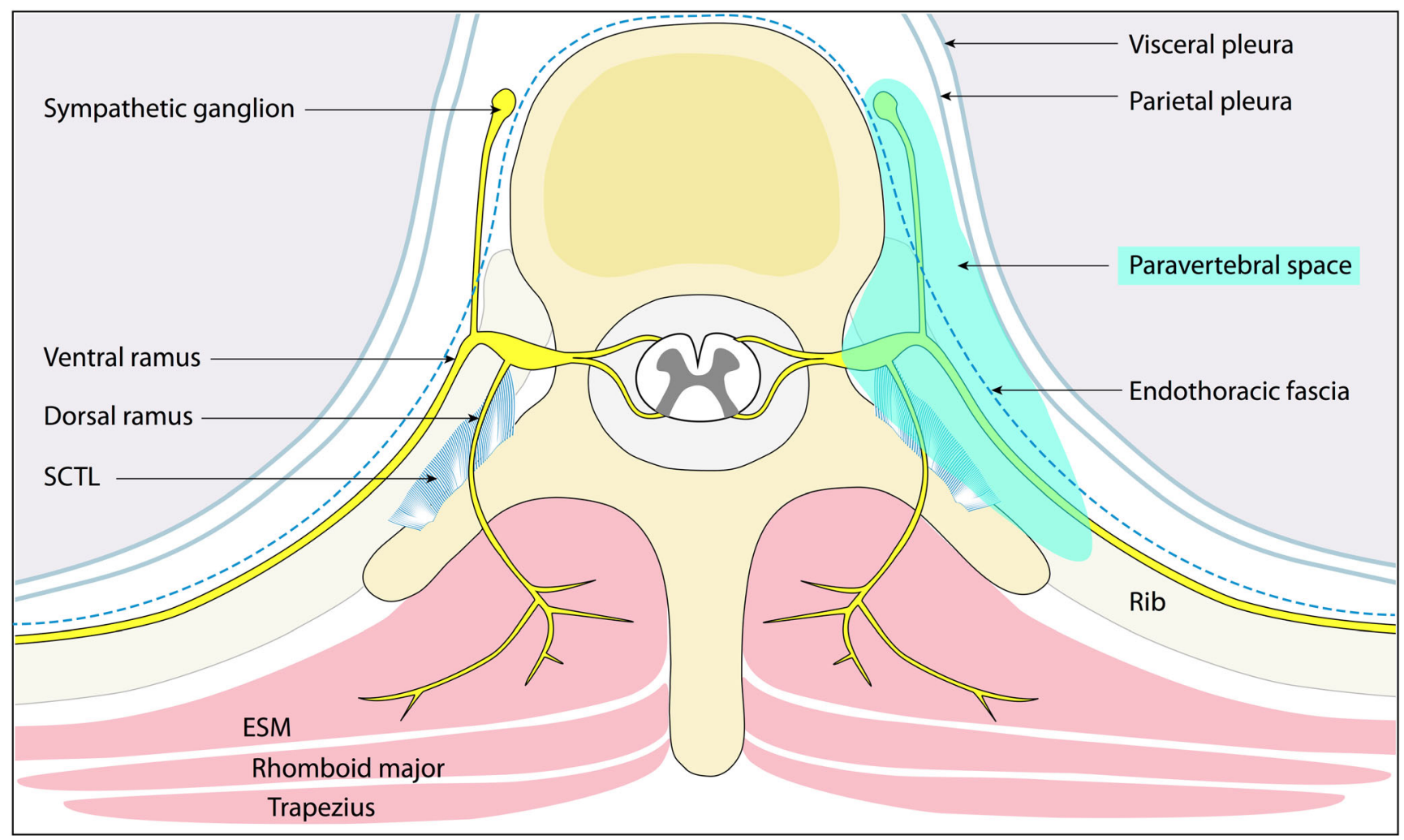

Fig. 1 Axial cross-section of a thoracic vertebra demonstrating key anatomical structures relevant to thoracic paravertebral block. ESM, erector spinae muscle; SCTL, superior costotransverse ligament 
Eason and Wyatt used a syringe filled with air for a loss of resistance technique, although saline can be used [21]. A "pop" or a "click" is sometimes felt and the change in resistance has been described as being subtle, unlike that felt during epidural insertion where the ligamentum flavum offers more robust resistance, and complete loss of resistance might actually indicate pleural puncture [21].

Once the needle has entered the paravertebral space and no blood, cerebral spinal fluid, or air is aspirated, a catheter can be threaded or a bolus of local anesthetic administered. Eason and Wyatt achieved four dermatome-level spread with a single injection of $15 \mathrm{~mL}$ bupivacaine $0.375 \%$. The authors recommend a volume of $20 \mathrm{~mL}$ and a long-acting local anesthetic, which is in accordance with published studies [22••, 23]. Catheter misplacement with the landmark technique is common, and this can lead to the failure to provide analgesia. Examination using fluoroscopy has shown catheter tips in the erector spinae muscle, the epidural, interpleural, and paravertebral spaces [24].

The needle may also be inserted using a "fixed predetermined distance approach." This is where the needle is walked off the transverse process as described above and advanced by a further $1-2 \mathrm{~cm}[19,25]$ without aiming to elicit a loss of resistance. This pre-determined technique might actually result in an injection that is posterior to the SCTL. This technique is thought to help negate the risk of accidental pleural puncture and inadvertent pneumothorax.

The use of pressure monitoring has also been described [20] with the use of a pressure transducer. The pressure in the erector spinae muscle in both inspiration and expiration exceeds the pressure in the space and always remains positive. This technique can help reduce the false-positive loss of resistance than can occur and also prevent the further advancement of the needle when penetration and crossing of the SCTL might not be fully appreciated.

Thermographic imaging studies have demonstrated that a five dermatome-level somatic blockade is achievable with a single-injection technique [17]. It is a common practice to perform a TPVB at the mid-point dermatome wishing to be blocked, for example T4 for breast or thoracic surgery [21].

\section{Ultrasound-Guided Thoracic Paravertebral Block}

Ultrasound has become an important tool in helping to identify and visualize anatomical landmarks and their depth [26]. It can also be used to aid real-time insertion which might increase block success and safety [3, 27]. Hara et al. first described the use of ultrasound for TPVB and used it to define the transverse processes and thoracic paravertebral space for real-time block performance. The needling technique described was out-of-plane, however, and the space was confirmed by loss of resistance as opposed to needle tip visualization [28].

Since then, other approaches have been described with the ultrasound transducer probe, typically a high-frequency linear array, in either the sagittal or paramedian and transverse orientation [22••]. The approaches described use different anatomical landmarks, typically the transverse process, rib, inferior articular process, or pleura; different needle paths; and either an in- or out-of-plane approach (Table 1) [22••]. It can be performed with the patient in the sitting, lateral, or prone positions.

The choice of technique to adopt is ultimately down to operator experience and preference; the ideal technique should be simple to perform and ensure continuous needle visualization and avoid the neuraxis. Currently, there is no evidence to conclude that one technique is superior to the other in terms of block success or the ability of the needle tip and injectate to cross the SCTL [22••]. Our suggested technique is in-plane needling with the probe in the sagittal (paramedian) orientation as this best visualizes the paravertebral space and ensures constant visualization of the needle shaft and tip. This does, however, require an acute insertion angle and longer needle path (Fig. 2). The use of an ultrasound-reflective Tuohy needle helps to provide better visualization and tactile feedback when the tip is seen crossing the SCTL. The risk of catheter migration into the epidural space is lower with this approach as the needle is pointing away from the midline [22••]. It also should be noted that a single-level injection can provide the equivalent spread of a multi-level technique [22••], and a total volume of $20 \mathrm{~mL}$ of a long-acting local anesthetic agent is commonly used. A "seeker" solution of saline can be used to ensure correct needle tip placement prior to injection of the local anesthetic.

\section{Indications}

The TPVB is most commonly performed unilaterally but it can also be performed bilaterally, provided the maximum dose of local anesthetic is not exceeded. There are a number of surgical and non-surgical indications for TPVBs, but the technique and approach remains similar (Table 2) [2, 3•, 22••, 30].

\section{Analgesic Efficacy}

\section{Thoracotomy}

Many studies focus on surgery involving thoracotomies as this is where the TPVB has been most widely adopted. A Cochrane systematic review concluded that the quality of analgesia delivered by TPVB via catheter is comparable 
Table 1 A summary of described ultrasound-guided approaches

\begin{tabular}{llll}
\hline Ultrasound probe position & Anatomical landmark & Needle path & In-plane or out-of-plane \\
\hline Transverse & Rib/intercostal & Lateral to medial & In-plane \\
Transverse & Transverse process & Lateral to medial & In-plane \\
Transverse & Transverse process & Caudad to cranial & Out-of-plane \\
Transverse & Inferior articular process & Lateral to medial & In-plane \\
Transverse & Inferior articular process & Medial to lateral & Out-of-plane \\
Sagittal & Rib/intercostal & Caudad to cranial & In-plane \\
Sagittal & Transverse process & Caudad to cranial & In-plane \\
Sagittal & Transverse process & Caudad to cranial & Out-of-plane \\
\hline
\end{tabular}

to thoracic epidural analgesia for thoracotomy, although the majority of studies included the insertion of TPVB catheters by surgeons under direct visualization [5•]. Regardless, TPVB catheters were non-inferior to thoracic epidurals for the first $24 \mathrm{~h}$ when pain scores were recorded at rest, on coughing or after physiotherapy. Other analyses have concluded that TPVB analgesia is equally effective up to $48 \mathrm{~h}[31,32]$.

\section{Abdominal Surgery}

A recent systematic review [3•] identified 20 trials examining the role of TPVB in abdominal surgery. It concluded that the analgesic outcomes in the early post-operative period favor TPVB when compared to systemic analgesia alone. No conclusions could be made regarding its comparison with regional techniques such as the transversus abdominis plane block, spinal or epidural analgesia. One trial compared a continuous catheter technique to thoracic
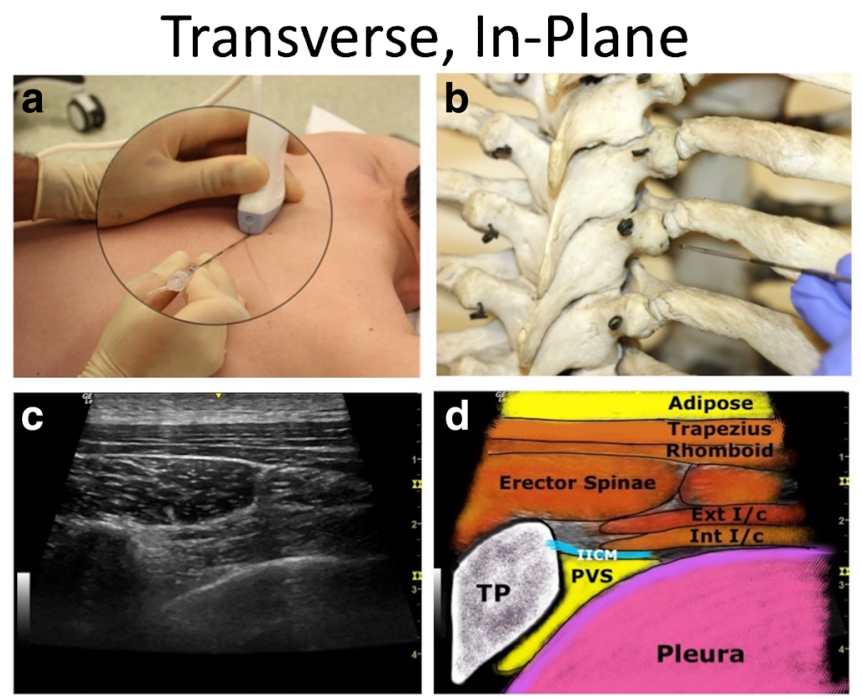

Fig. 2 The transverse in-plane and paramedian sagittal in-plane approaches to the paravertebral block. (A) The probe and needle orientation. (B) Needle direction in relation to the transverse process and vertebral body. (C) Ultrasound image. (D) Schematic anatomy. Ext epidural in open cholecystectomy and found it to be inferior [33].

\section{Breast Surgery}

When compared to systemic analgesia alone, the singleinjection TPVB has been shown to significantly reduce intra- and post-operative opioid consumption and decrease post-operative pain scores [27, 30, 34-36]. The benefits might

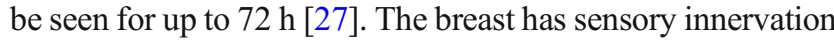
from the intercostobrachial, medial pectoral, and lateral pectoral nerves. These are often not reliably blocked by the TPVB which is important to note, especially if the surgery involves the axilla. In this scenario, the Pecs II block can provide superior analgesia to the TPVB alone [37].

\section{Chronic Post-Surgical Pain}

The role in chronic post-surgical pain (CPSP) following breast surgery suggests potential benefits of TPVB, compared to
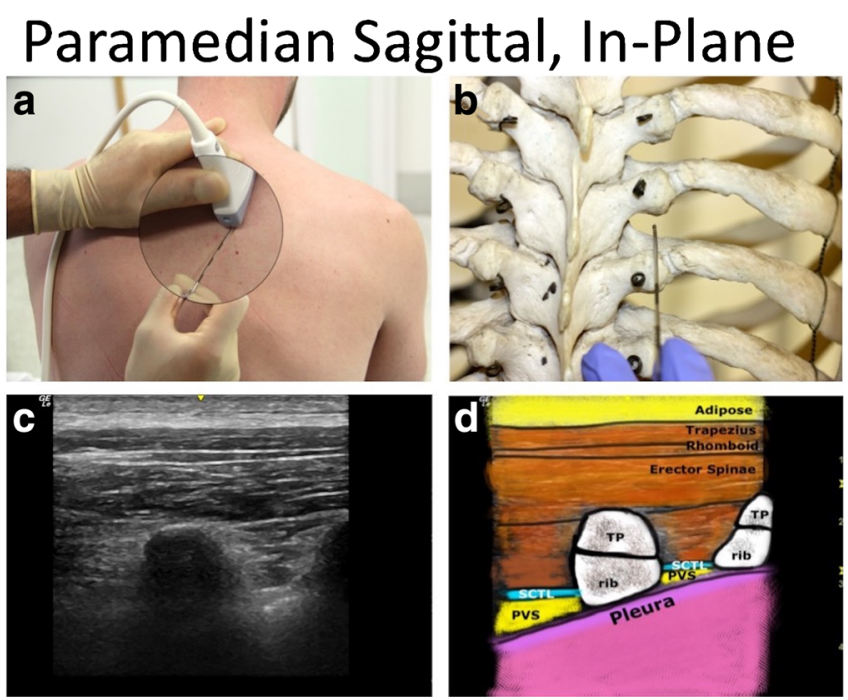

I/c, external Intercostal muscle; Int I/c, internal intercostal muscle; TP, transverse process; IICM, internal intercostal membrane; PVS, paravertebral space; SCTL, superior costotransverse ligament 
Table 2 Common surgical and non-surgical indications for TPVB

\begin{tabular}{llll}
\hline & Surgical & & Non-surgical \\
\hline Acute & Thoracic & Abdominal & \\
& - Lung & - Inguinal hernia repair & - Rib fractures \\
& - Cardiac & - Renal & \\
& - Aortic & - Cholecystectomy & \\
& - Spine & - Gynecological (open) & \\
& - Esophageal & & \\
& - Breast & & - Post-herpetic neuralgia [29] \\
& Chronic post-surgical pain &
\end{tabular}

systemic analgesics alone [27]. Whilst there may be a signal that CPSP is reduced following breast surgery with TPVB [27], and might reduce symptom severity [38], there is a dearth of high-quality, adequately powered studies to make definitive conclusions in different patient populations [5•].

\section{Complications}

Despite the TPVB being performed for a number of decades, it was not until the 1990s that the failure rate and complications were prospectively studied [39]. Up to that point, complications, particularly vascular puncture or pneumothorax [18], were poorly investigated. However, systematic reviews and meta-analyses have been conducted $[3 \bullet, 5 \bullet, 27]$ to clarify the safety of TPVB. The definition of "block failure" varies in the published literature. These include higher than expected pain scores [39], no block on dermatomal testing [39], the inability to access the PVS [5•, 27], or "block failure" as a general term for failure of surgical anesthesia [3•]. Many studies do not comment on systematically assessing for block success.

The landmark technique failure rate appears to be higher than the ultrasound guided $[3 \bullet, 27]$ with quoted rates between 1.98 and $5.6 \%$. The loss of resistance approach failure rate is reportedly higher $(5.2 \%)$ than the pre-determined distance approach $(2.3 \%)$ [3•]. Failure rates in the ultrasound-guided approach are lower ( 0 to $2.3 \%$ ), although the case numbers available for analysis are smaller $[3 \bullet, 27]$.

The reported complications rates are low in both the landmark and ultrasound-guided techniques, with hypotension and epidural spread reported as $2.1 \%$ and vascular puncture,

Table 3 Recently described paraspinal "paravertebral by proxy" techniques

\begin{tabular}{|c|c|c|c|c|}
\hline Block & $\begin{array}{l}\text { Erector spinae plane block } \\
(\text { ESPB) }[42,45-51]\end{array}$ & $\begin{array}{l}\text { Mid-point transverse process } \\
\text { to pleura block (MTP) }[43,52]\end{array}$ & $\begin{array}{l}\text { Retro-laminar block (RLB) } \\
\text { [53-55] }\end{array}$ & $\begin{array}{l}\text { Intercostal paraspinal block } \\
{[56,57]}\end{array}$ \\
\hline $\begin{array}{l}\text { Transducer } \\
\text { position }\end{array}$ & $\begin{array}{l}\text { Linear ultrasound probe placed } \\
\text { on the transverse process. } \\
\text { Paramedian plane }\end{array}$ & $\begin{array}{l}\text { Linear ultrasound probe is } \\
\text { placed on the transverse } \\
\text { process. Paramedian plane }\end{array}$ & $\begin{array}{l}\text { Linear/curvilinear probe is } \\
\text { placed on the vertebral laminae. } \\
\text { Paramedian plane }\end{array}$ & $\begin{array}{l}\text { Linear ultrasound probe is } \\
\text { placed more laterally at the ribs. } \\
\text { Paramedian plane }\end{array}$ \\
\hline $\begin{array}{l}\text { Sono-anatomical } \\
\text { landmarks }\end{array}$ & $\begin{array}{l}\text { Identify trapezius, rhomboid } \\
\text { major and erector spinae muscle } \\
\text { groups superficial to the } \\
\text { transverse process }\end{array}$ & $\begin{array}{l}\text { Identify the top of the } \\
\text { transverse process and pleura }\end{array}$ & $\begin{array}{l}\text { Scan lateral to medial } \\
\text { visualizing ribs, then transverse } \\
\text { processes and the vertebral } \\
\text { laminae. Identify the vertebral } \\
\text { laminae and the erector spinae } \\
\text { muscles }\end{array}$ & $\begin{array}{l}\text { Identify rhomboid major and } \\
\text { intercostal muscles }\end{array}$ \\
\hline Needle trajectory & $\begin{array}{l}\text { In-plane, cephalad to caudad } \\
\text { direction (or vice-versa), } \\
\text { towards the transverse process }\end{array}$ & $\begin{array}{l}\text { In-plane, caudad to cephalad } \\
\text { direction towards the } \\
\text { paravertebral space }\end{array}$ & $\begin{array}{l}\text { In-plane, cephalad or caudad } \\
\text { direction }\end{array}$ & $\begin{array}{l}\text { In-plane, cephalad to caudad } \\
\text { direction }\end{array}$ \\
\hline Point of injection & $\begin{array}{l}\text { Contact the transverse process } \\
\text { with the needle and inject deep } \\
\text { to the erector spinae muscles }\end{array}$ & $\begin{array}{l}\text { Mid-point between the } \\
\text { posterior border of transverse } \\
\text { process and the pleura }\end{array}$ & $\begin{array}{l}\text { Contact the lamina and inject in } \\
\text { the plane between the lamina of } \\
\text { the thoracic vertebra and the } \\
\text { erector spinae muscles. } \\
\text { Injection is more medial than an } \\
\text { ESPB }\end{array}$ & $\begin{array}{l}\text { Fascial plane between the } \\
\text { rhomboid and the intercostal } \\
\text { muscles }\end{array}$ \\
\hline Indications & $\begin{array}{l}\text { Use described for thoracics, } \\
\text { breast surgery, rib fractures, } \\
\text { ventral hernia repair, abdominal } \\
\text { surgery, and spinal surgery }\end{array}$ & $\begin{array}{l}\text { Use described for breast } \\
\text { surgery and video-assisted } \\
\text { thoracoscopic surgery }\end{array}$ & $\begin{array}{l}\text { Use described for breast surgery } \\
\text { and rib fractures }\end{array}$ & $\begin{array}{l}\text { Use described in rib fractures } \\
\text { and thoracic surgery }\end{array}$ \\
\hline
\end{tabular}


pneumothorax, and nerve damage all less than $1 \%$ [27]. A retrospective review of 1500 ultrasound-guided blocks reported no cases of accidental pleural puncture or symptomatic pneumothorax [40॰], although prospective data is distinctly lacking and therefore no definitive conclusions can yet be made. Short-term post-operative outcomes such as respiratory complications, re-admissions to intensive care units, or length of stay also appear to be similar between TPVB and thoracic epidural analgesia in thoracic surgery [41], although, once again, definitive conclusions cannot be drawn from this retrospective data as yet.

\section{Paraspinal Techniques}

The availability and use of ultrasound has given alternative approaches the TPVB. Integral to the ultrasound-guided techniques is the desire for the needle and the local anesthetic to cross the SCTL. However, a number of new techniques have successfully achieved paravertebral spread and thoracic nerve blockade without the needle actually entering the space [42-44]. These have been described as being "paravertebral by proxy" [12•].

A number of paraspinal techniques have been described (Table 3); the erector spinae plane block [42], the mid-point transverse process to pleura block [43], the retro-laminar block [53], and the intercostal paraspinal block [56] (Table 3). These innovative blocks have challenged the notion that TPVB can only be achieved by injection within the PVS [58]. These blocks may achieve local anesthetic spread to thoracic spinal nerves through the connective tissue and gaps that surround the PVS [42, 43, 45], without the need to enter the PVS $[2,42,43,59]$. These blocks avoid needle placement close to the pleura and neurovascular structures [53] and may increase the utilization of regional anesthetic techniques [60]. The evidence base for many of these techniques remains limited, but is an important avenue of investigation.

\section{Conclusions}

For many, the thoracic epidural remains the gold standard for analgesia of the thorax and abdomen.

However, there is growing evidence to suggest that the TPVB offers at least non-inferior analgesia and failure rates. Furthermore, the low complication rates and the ability to increase block success with the use of ultrasound make the TPVB an increasingly appealing technique to perform. The paraspinal approaches are being described and although we are currently unsure to their exact mechanism of action, their discovery might represent a novel way of indirectly accessing the paravertebral space.

\section{Compliance with Ethical Standards}

Conflict of Interest Amit Pawa has received compensation from GE Healthcare, B. Braun Medical, and MedaPhor for service as a consultant.

Thomas Wojcikiewicz has received reimbursement for travel expenses from Baxter Polska and Fisher \& Paykel.

Ann Barron declares that she has no conflict of interest.

Kariem El-Boghdadly has received compensation from Ambu for service as a consultant.

Human and Animal Rights and Informed Consent This article does not contain any studies with human or animal subjects performed by any of the authors.

Open Access This article is distributed under the terms of the Creative Commons Attribution 4.0 International License (http:// creativecommons.org/licenses/by/4.0/), which permits unrestricted use, distribution, and reproduction in any medium, provided you give appropriate credit to the original author(s) and the source, provide a link to the Creative Commons license, and indicate if changes were made.

\section{References}

Papers of particular interest, published recently, have been highlighted as:

- Of importance

•• Of major importance

1. Richardson J, Lönnqvist PA. Thoracic paravertebral block. Br J Anaesth. 1998;81:230-8.

2. Wild $\mathrm{K}$, Chin KJ. Regional techniques for thoracic wall surgery. Curr Anesthesiol Rep. 2017;7:212-9. https://doi.org/10.1007/ s40140-017-0212-y.

3. El-Boghdadly K, Madjdpour C, Chin KJ. Thoracic paravertebral blocks in abdominal surgery - a systematic review of randomized controlled trials. Br J Anaesth. 2016;117:297-308 A review of the randomized-controlled trials using TPVB for abdominal surgery.

4. Kavanagh B, Katz J, Sandler A. Pain control after thoracic surgery. A review of current techniques. Anesthesiology. 1994;81:737-59.

5. Yeung JH, Gates S, Naidu B V, Wilson MJ (2016) Paravertebral block versus thoracic epidural for patients undergoing thoracotomy. Cochrane Database Syst Rev. 2016. https://doi.org/10.1002/ 14651858.cd009121.pub2. A systematic review of TPVB in thoracotomy.

6. Klein SM, Greengrass RA, Weltz CWD. Paravertebral somatic nerve block for outpatient inguinal herniorhaphy; an extended case report of 22 patients. Reg Anesth Pain Med. 1998;23:306-10.

7. Kairaluoma PM, Bachmann MS, Rosenberg PH, Pere PJ. Preincisional paravertebral block reduces the prevalence of chronic pain after breast surgery. Anesth Analg. 2006;103:703-8.

8. Pawa A, Wight J, Onwochei DN, Vargulescu R, Reed I, Chrisman $\mathrm{L}$, et al. Combined thoracic paravertebral and pectoral nerve blocks for breast surgery under sedation: a prospective observational case series. Anaesthesia. 2018;73:438-43.

9. Wigmore TJ, Mohammed K, Jhanji S. Long-term survival for patients undergoing volatile versus IV anesthesia for cancer surgery: a retrospective analysis. Anesthesiology. 2016;124:69-79.

10. Heaney Á, Buggy DJ. Can anaesthetic and analgesic techniques affect cancer recurrence or metastasis? Br J Anaesth. 2012;109: i17-28. 
11. Perry NJS, Ma D. Inhalational anesthetic agents and their effects on cancer cell biology. Curr Anesthesiol Rep. 2015;5:268-77.

12. Costache I, Pawa A, Abdallah FW. Paravertebral by proxy - time to redefine the paravertebral block. Anaesthesia. 2018;73:1185-8. https://doi.org/10.1111/anae.14348. An overview of recently described blocks that might exert their effect by spread to the paravertebral space.

13. Ibrahim AF, Darwish HH. The costotransverse ligaments in human: a detailed anatomical study. Clin Anat. 2005;18(5):340-5.

14. Luyet C, Herrmann G, Ross S, Vogt A, Greif R, Moriggl B, et al. Ultrasound-guided thoracic paravertebral puncture and placement of catheters in human cadavers: where do catheters go? Br J Anaesth. 2011;106:246-54.

15. Klein SM, Nielsen K, Ahmed N, Buckenmaier CSS. In situ images of the thoracic paravertebral space. Reg Anesth Pain Med. 2004;29: 596-9.

16. Lönnqvist PA, Hildingsson $U$. The caudal boundary of the thoracic paravertebral space. Anaesthesia. 1992;47:1051-2.

17. Cheema SPS, Ilsley D, Richardson J, Sabanathan S. A thermographic study of paravertebral analgesia. Anaesthesia. 1995;50: 118-21.

18. Eason MJ, Wyatt R. Paravertebral thoracic block: a reappraisal. Anaesthesia. 1979;34:638-42.

19. Gilbert J, Hultman J. Thoracic paravertebral block: a method of pain control. Acta Anaesthesiol Scand. 1989;33:142-5.

20. Richardson J, Cheema SPS, Hawkins J, Sabanathan S. Thoracic paravertebral space location: a new method using pressure measurement. Anaesthesia. 1996;51:137-9.

21. Tighe S, Greene MD, Rajadurai N. Paravertebral block. Contin Educ Anaesth Crit Care Pain. 2010;10:133-7.

22.• Krediet AC, Moayeri N, van Geffen G-J, Bruhn J, Renes S, Bigeleisen PE, et al. Different approaches to ultrasound-guided thoracic paravertebral block. Anesthesiology. 2015;123:459-74 An extremely thorough summary of ultrasound-guided techniques using images of cadaveric tissue and ultrasound views.

23. Shibata Y, Nishiwaki K. Ultrasound-guided intercostal approach to thoracic paravertebral block. Anesth Analg. 2009;109:996-7.

24. Luyet C, Siegenthaler A, Hummel G, Eichenberger U, Vogt A. The location of paravertebral catheters placed using the landmark technique. Anaesthesia. 2012;67:1321-6.

25. Greengrass R, O’Brien F, Lyerly K, Hardman D, Gleason D, D'Ercole FSS. Paravertebral block for breast cancer surgery. Can J Anaesth. 1996;43:858-61.

26. Pusch F, Wildling E, Klimscha W, Weinstabl C. Sonographic measurement of needle insertion depth in paravertebral blocks in women. Br J Anaesth. 2000;85:841-3.

27. Terkawi AS, Tsang S, Sessler DI, Terkawi RS, Nunemaker MS, Durieux ME, et al. Improving analgesic efficacy and safety of thoracic paravertebral block for breast surgery: a mixed-effects metaanalysis; 2015. p. 757-80.

28. Hara K, Sakura S, Nomura T, et al. Ultrasound guided thoracic paravertebral block in breast surgery. Anaesthesia. 2009;64:223-5.

29. Makharita MY, Amr YM, El-Bayoumy Y. Single paravertebral injection for acute thoracic herpes zoster: a randomized controlled trial. Pain Pract. 2015;15:229-35.

30. Wardhan R. Update on paravertebral blocks. Curr Opin Anaesthesiol. 2015;28:588-92.

31. Baidya DK, Khanna P, Maitra S. Analgesic efficacy and safety of thoracic paravertebral and epidural analgesia for thoracic surgery: a systematic review and meta-analysis. Interact Cardiovasc Thorac Surg. 2014;18(5):626-35. https://doi.org/10.1093/icvts/ivt551.

32. Ding X, Jin S, Niu X, Ren H, Fu S, Li Q. A comparison of the analgesia efficacy and side effects of paravertebral compared with epidural blockade for thoracotomy: an updated meta-analysis. PLoS One. 2014;9:e96233. https://doi.org/10.1371/journal.pone. 0096233
33. Bigler D, Dirkes W, Hansen R, Rosenberg J, Kehlet H. Effects of thoracic paravertebral block with bupivacaine versus combined thoracic epidural block with bupivacaine and morphine on pain and pulmonary function after cholecystectomy. Acta Anaesthesiol Scand. 1989;33:561-4.

34. Pei L, Zhou Y, Tan G, et al. Ultrasound-assisted thoracic paravertebral block reduces intraoperative opioid requirement and improves analgesia after breast cancer surgery: a randomized, controlled, single-center trial. PLoS One. 2015;10:1-15.

35. Wu J, Buggy D, Fleischmann E, Parra-Sanchez I, Treschan T, Kurz A, et al. Thoracic paravertebral regional anesthesia improves analgesia after breast cancer surgery: a randomized controlled multicentre clinical trial. Can J Anaesth. 2015;62:241-51.

36. Schnabel A, Reichl SU, Kranke P, Pogatzki-Zahn EM, Zahn PK. Efficacy and safety of paravertebral blocks in breast surgery: a meta-analysis of randomized controlled trials. Br J Anaesth. 2010;105:842-52.

37. Kulhari S, Bharti N, Bala I, Arora S, Singh G. Efficacy of pectoral nerve block versus thoracic paravertebral block for postoperative analgesia after radical mastectomy: a randomized controlled trial. Br J Anaesth. 2016;117:382-6.

38. Karmakar MK, Samy W, Li JW, Lee A, Chan WC, Chen PP, et al. Thoracic paravertebral block and its effects on chronic pain and health-related quality of life after modified radical mastectomy. Reg Anesth Pain Med. 2014;39:289-98.

39. Lönnqvist PA, MacKenzie J, Soni AK, Conacher ID. Paravertebral blockade: failure rate and complications. Anaesthesia. 1995;50: 1994-6.

40. Pace MM, Sharma B, Anderson-dam J, Fleischmann K, Warren L, Stefanovich P. Ultrasound-guided thoracic paravertebral blockade: a retrospective study of the incidence of complications. Anesth Analg. 2016;122:1186-91 This large retrospective analysis concludes that the ultrasound-guided technique carries a low risk of complications.

41. Blackshaw WJ, Bhawnani A, Pennefather SH, Al-Rawi O, Agarwal S, Shaw M. Propensity score-matched outcomes after thoracic epidural or paravertebral analgesia for thoracotomy. Anaesthesia. 2018;73:444-9.

42. Forero M, Adhikary SD, Lopez H, Tsui C, Chin KJ. The erector spinae plane block a novel analgesic technique in thoracic neuropathic pain. Reg Anesth Pain Med. 2016;41:621-7.

43. Costache I, de Neumann L, Ramnanan CJ, Goodwin SL, Pawa A, Abdallah FW, et al. The mid-point transverse process to pleura (MTP) block: a new end-point for thoracic paravertebral block. Anaesthesia. 2017;72:1230-6.

44. Murouchi T, Yamakage M. Retrolaminar block: analgesic efficacy and safety evaluation. J Anesth. 2016;30:1003-7.

45. Tsui BCH, Fonseca A, Munshey F, Mcfadyen G, Caruso TJ (2018) The erector spinae plane (ESP) block: a pooled review of 242 cases. J Clin Anesth. 2019;53:29-34.

46. Chin KJ, Adhikary S, Sarwani N, Forero M. The analgesic efficacy of pre-operative bilateral erector spinae plane (ESP) blocks in patients having ventral hernia repair. Anaesthesia. 2017;72:452-60. https://doi.org/10.1111/anae.13814.

47. Ueshima H, Otake H. Erector spinae plane block provides effective pain management during pneumothorax surgery. J Clin Anesth. 2017;40:74.

48. Ohgoshi Y, Ikeda T, Kurahashi K. Continuous erector spinae plane block provides effective perioperative analgesia for breast reconstruction using tissue expanders: a report of two cases. J Clin Anesth. 2018;44:1-2.

49. Hamilton DL, Manickam B. Erector spinae plane block for pain relief in rib fractures. Br J Anaesth. 2017;118:474-5.

50. Restrepo-Garces CE, Chin KJ, Suarez P, Diaz A. Bilateral continuous erector spinae plane block contributes to effective postoperative 
analgesia after major open abdominal surgery. A A Case Rep. 2017;9:319-21.

51. Melvin J, Schrot R, Chu GCK. Low thoracic erector spinae plane block for perioperative analgesia in lumbosacral surgery: a case series. Can J Anaesth. 2018;65:1057-65.

52. Scimia P, Fusco P, Droghetti A, Harizaj FBRE. The ultrasoundguided mid-point transverse process to pleura block for postoperative analgesia in video-assisted thoracoscopic surgery. Minerva Anestesiol. 2018;84:767-8.

53. Voscopoulos C, Palaniappan D, Zeballos J, Ko H, Janfaza D, Vlassakov K. The ultrasound-guided retrolaminar block. Can J Anesth. 2013;60:888-95. https://doi.org/10.1007/s12630-0139983-x.

54. Sabouri AS, Crawford L, Bick SK, Nozari A, Anderson TA. Is a retrolaminar approach to the thoracic paravertebral space possible? Reg Anesth Pain Med. 2018;43:1.

55. Jüttner $\mathrm{T}$, Werdehausen $\mathrm{R}$, Hermanns $\mathrm{H}$, et al. The paravertebral lamina technique: a new regional anesthesia approach for breast surgery. J Clin Anesth. 2011;23:443-50.
56. Elsharkawy H, Saifullah T, Kolli SDR. Rhomboid intercostal block. Anaesthesia. 2016;71:856-7.

57. Roué C, Wallaert M, Kacha M, Havet E. Intercostal/paraspinal nerve block for thoracic surgery. Anaesthesia. 2016;71:112-3. https://doi.org/10.1111/anae.13358.

58. Costache I, Sinclair J, Farrash FA, Nguyen TB, McCartney CJL, Ramnanan CJ, et al. Does paravertebral block require access to the paravertebral space? Anaesthesia. 2016;71:858-9.

59. Yang H-M, Choi YJ, Kwon H-J, Cho TH, Kim SH. Comparison of injectate spread and nerve involvement between retrolaminar and erector spinae plane blocks in the thoracic region: a cadaveric study. Anaesthesia. 2018;73(10):1244-50. https://doi.org/10.1111/anae. 14408 .

60. El-Boghdadly K, Pawa A. The erector spinae plane block: plane and simple. Anaesthesia. 2017;72:434-8.

Publisher's Note Springer Nature remains neutral with regard to jurisdictional claims in published maps and institutional affiliations. 